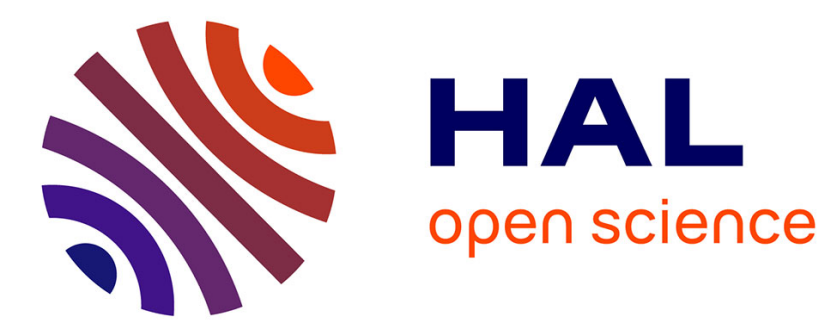

\title{
Study of 18 functional hemostatic polymorphisms in mucocutaneous bleeding disorders
}

Ana I. Antón, Rocio González-Conejero, Vanessa Roldán, Teresa Quiroga, Beatriz Sánchez-Vega, Javier Corral, Vicente Vicente, Diego Mezzano

\section{To cite this version:}

Ana I. Antón, Rocio González-Conejero, Vanessa Roldán, Teresa Quiroga, Beatriz Sánchez-Vega, et al.. Study of 18 functional hemostatic polymorphisms in mucocutaneous bleeding disorders. Annals of Hematology, 2010, 89 (11), pp.1147-1154. 10.1007/s00277-010-1000-7 . hal-00544809

\author{
HAL Id: hal-00544809 \\ https://hal.science/hal-00544809
}

Submitted on 9 Dec 2010

HAL is a multi-disciplinary open access archive for the deposit and dissemination of scientific research documents, whether they are published or not. The documents may come from teaching and research institutions in France or abroad, or from public or private research centers.
L'archive ouverte pluridisciplinaire HAL, est destinée au dépôt et à la diffusion de documents scientifiques de niveau recherche, publiés ou non, émanant des établissements d'enseignement et de recherche français ou étrangers, des laboratoires publics ou privés. 


\section{Editorial Manager(tm) for Annals of Hematology}

Manuscript Draft

Manuscript Number: AOHE-D-10-00016R1

Title: Study of 18 functional hemostatic polymorphisms in mucocutaneous bleeding disorders

Article Type: Original Article

Keywords: mucocutaneous bleeding; mild bleeding disorders; gene polymorphism; thrombosis

Corresponding Author: Dr Anabel Anton, Ph.D

Corresponding Author's Institution:

First Author: Anabel Anton, Ph.D

Order of Authors: Anabel Anton, Ph.D; Rocio González-Conejero; Vanessa Roldán; Teresa Quiroga;

Beatriz Sánchez-Vega; Javier Corral; Vicente Vicente; Diego Mezzano

Abstract: Hereditary disorders of primary haemostasis, characterized by mucocutaneous bleeding (MCB), are highly prevalent in children. Few cases are clearly monogenic but the overwhelming majority are classified as mild bleeding disorders, with wide clinical and laboratory heterogeneity suggestive of complex polygenic diseases. In this framework, and by homology with venous thrombosis, some functional polymorphisms affecting the haemostatic system should be considered. We evaluated the role of 18 common haemostatic polymorphisms on the occurrence and severity of MCB in a casecontrol study including 269 patients and 286 matched controls consecutively recruited. FV Leiden was associated with milder bleeding severity, assessed by a standardized bleeding score $(p=0.013)$.

Multivariate analysis revealed that three additional polymorphisms protected against MCB (F13 Leu34, OR=0.66, 95\%CI:0.47-0.94, p=0.024; VKORC1 1173T, OR=0.59, 95\%CI:0.40-0.87, $\mathrm{p}=0.009$; and non-0 blood group alleles, OR=0.59, 95\%CI:0.41-0.86, $\mathrm{p}=0.006)$. When combined, these polymorphisms showed an additive protection (OR=0.24; 95\% CI:0.11-0.52), supporting the polygenic nature of MCB. Our data suggest that some common polymorphisms affecting haemostasis-related genes could protect from bleeding.

Response to Reviewers: see attachment 
*Conflict of interest
Click here to downloa

Click here to download Conflict of interest: Conflict of interest_Al.Anton.doc

Hoad Conflict of interest: Conflict of interest_Al.Anton.doc 
Study of 18 functional hemostatic polymorphisms in mucocutaneous bleeding disorders.

Ana I. Antón, ${ }^{1}$ Rocio González-Conejero, ${ }^{1}$ Vanessa Roldán, ${ }^{1}$ Teresa Quiroga, ${ }^{2}$ Beatriz Sánchez-Vega, ${ }^{1}$ Javier Corral, ${ }^{1}$ Vicente Vicente, ${ }^{1}$ and Diego Mezzano ${ }^{2}$

${ }^{1}$ University of Murcia; Centro Regional de Hemodonación; Murcia. Spain. ${ }^{2}$ Department of Hematology-Oncology; School of Medicine; P. Universidad Católica de Chile; Santiago, Chile

Running head: Haemostatic SNPs in mucocutaneous bleeding

\section{Address for Correspondence:}

Vicente Vicente García

Centro Regional de Hemodonación

Ronda de Garay s/n

30003, Murcia

Spain

Tel: +34968341990

Fax: +34 968261914

e-mail: vicente.vicente@carm.es

Word Count: 2454 


\begin{abstract}
Hereditary disorders of primary haemostasis, characterized by mucocutaneous bleeding (MCB), are highly prevalent in children. Few cases are clearly monogenic but the overwhelming majority are classified as mild bleeding disorders, with wide clinical and laboratory heterogeneity suggestive of complex polygenic diseases. In this framework, and by homology with venous thrombosis, some functional polymorphisms affecting the haemostatic system should be considered. We evaluated the role of 18 common haemostatic polymorphisms on the occurrence and severity of MCB in a case-control study including 269 patients and 286 matched controls consecutively recruited. FV Leiden was associated with milder bleeding severity, assessed by a standardized bleeding score $(\mathrm{p}=0.013)$. Multivariate analysis revealed that three additional polymorphisms protected against MCB (F13 Leu34, OR=0.66, 95\%CI:0.47-0.94, $\mathrm{p}=0.024 ;$ VKORC1 $1173 \mathrm{~T}, \mathrm{OR}=0.59,95 \% \mathrm{CI}: 0.40-0.87, \mathrm{p}=0.009 ;$ and non-O blood group alleles, $\mathrm{OR}=0.59,95 \% \mathrm{CI}: 0.41-0.86, \mathrm{p}=0.006)$. When combined, these polymorphisms showed an additive protection ( $\mathrm{OR}=0.24 ; 95 \%$ CI:0.11-0.52), supporting the polygenic nature of MCB. Our data suggest that some common polymorphisms affecting haemostasis-related genes could protect from bleeding.
\end{abstract}

\title{
Word count: 163
}

Key words: mucocutaneous bleeding, mild bleeding disorders, gene polymorphism, thrombosis 


\section{Introduction}

The haemostatic system has evolved in the animal kingdom to protect against fatal hemorrhages. A finely regulated interaction of platelets and haemostatic factors generates protective plugs preventing blood loss at sites of vascular injury. Disturbances in such interaction by structural anomalies or changes in levels of critical components of haemostasis are pathologically translated in either bleeding or thrombotic complications. Multiple gene mutations encoding natural inhibitors of the clotting process result in loss of plasma concentration/function of these proteins, i.e., antithrombin, proteins $\mathrm{S}$ or $\mathrm{C}$, and are associated to high risk of venous thrombosis. The pathogenic predominance of these mutations in triggering thrombotic events supports, at least in some cases, that these single mutations have predominant contribution in the disease. However, the notion that venous thrombosis is a polygenic, complex disorder, gained support after identifying two common prothrombotic polymorphisms, factor V Leiden (FVL) and prothrombin G20210A [1, 2]. Since then, hundreds of studies have assessed the role of many polymorphisms as putative risk factors for thrombosis; however, the conclusions of many of them are discrepant [3-6]. Mucocutaneous bleeding (MCB) has high prevalence in children [7, 8]. A minority, constituting the more severe disorders, results from mutations affecting major platelet glycoproteins (i.e., GPIIb-IIIa or GPIb-V-IX) or plasma factors (i.e., complete absence of von Willebrand factor). In these cases, the symptoms can be explained almost exclusively by a single mutation determining defects in critical functions of plateletvessel wall interaction. However, an overwhelming proportion of disorders manifested with MCB symptoms fall in the category of "mild bleeding disorders", including most types of von Willebrand disease and platelet functional defects. In this category are also included more than $50 \%$ of all patients with MCB who remain undiagnosed after comprehensive laboratory studies [9]. These disorders are likely multifactorial, as is the case with most venous thrombosis $[5,6]$. 
In this regard, the frequency of combined bleeding defects is greater than that predicted by chance [10], supporting and enlarging the notion initially raised by Sadler, who proposed that low VWF levels (and by extension some platelet function defects) should be considered risk factors rather than unique bleeding causes [11]. In a similar context, prothrombotic polymorphisms are reported to reduce the clinical severity of haemophilias [12]. Thus, it would be expected that functional haemostatic polymorphisms commonly regarded as procoagulants, modulate the clinical expression of bleeding disorders [13].

Now, we investigated the influence of 18 polymorphisms on the risk and bleeding severity in a case-control study involving 269 patients with MCB and 286 matched controls. These polymorphisms were selected by their relevant effect on different hemostatic proteins, as they affect the levels, function or aminoacid sequence, and all them have been extensively evaluated in different hemostatic diseases, mainly thrombotic disorders.

\section{Materials and Methods}

\section{Patients}

The Clinical Ethics Committee of the P. Catholic University of Chile approved this research. Blood samples were obtained after written informed consent, according to the Declaration of Helsinki. Consecutive patients (aged $\geq 4$ years and $\leq 50$ years), referred by physicians aware of the objectives of the study, were always interviewed by the same investigator using a standardized questionnaire [14], modified to assess mainly mucous and skin bleeding. The interviewer recorded the current and past bleeding episodes independently of the age at consultation. Briefly, the most frequent and typical symptoms (Table 1) were scored from 0 to 4 , according to their frequency, duration, recurrence, and need and type of therapy. Other symptoms, of lesser frequency, less typical of primary haemostasis disorders, or those present only after exposure to risk, 
were scored 0 (absent) or 1 (present). The recorded data were processed later providing a numerical assessment of bleeding severity (bleeding score, BS). Finally, the study included 269 patients (mean age 14.5 years, 60\% female) who had pathologic bleeding. The controls, recruited independently of the patients with similar geographical, ethnic, social, economic and cultural background, were matched for age and sex (mean age 12.3 years, 55\% female), and subjected to the same interview and exclusion criteria as the patients, selecting only non-bleeders $(n=253)$ or trivial bleeders $(n=24)$. Blood sampling processing, laboratory tests and diagnostic criteria for platelet function disorders, von Willebrand disease (VWD) and clotting factors deficiencies were described before [10]. Clinical characteristics, frequency of diagnosis and demographic data of patients and controls were previously reported [10]. Briefly, 39 patients $(14.5 \%)$ had VWD, $50(18.6 \%)$ had platelet dysfunction, 7 (2.6\%) had coagulation factor deficiency and $13(4.8 \%)$ had any combination of the previous three diagnosis. The remaining 160 patients $(59.5 \%)$ had bleeding of unknown cause, classified in this category after a comprehensive laboratory work up.

\section{Genotyping}

Functional polymorphisms affecting the haemostatic system and methods of analysis are summarized in Table 2 [15-19]. The selection of these polymorphisms was carried out in terms of their functional effect and relevance reported in haemostatic diseases, mainly thrombotic disorders. Some of them have been previously shown to affect the plasma levels or functional effects of clotting factors or modify the bleeding severity in patients with hemorrhagic disorders.

We genotyped 18 polymorphisms affecting platelets; coagulation or fibrinolysis factors and others with haemostatic roles and ABO blood group. DNA was extracted by standard methods and Real Time PCR reactions were performed on a LC480 PCR 
system (Roche). Direct sequencing was performed for randomly selected samples to confirm genotyping results. The $\mathrm{ABO}$ blood group was determined using standard agglutination techniques.

\section{Statistical Analysis}

Statistical analysis was performed using the Statistical Package for Social Science (version 15.0; SPSS, Chicago, IL, USA). Allele and genotype frequencies and deviations from Hardy-Weinberg expectations were calculated with the SNPstats software [20]. Continuous variables were tested for normal distribution by KolmogorovSmirnov's test. Data exhibiting normal or non-normal distribution are presented as mean \pm standard deviation (SD) and as median and interquartile range (IQR), respectively. Categorical variables were compared by Pearson chi-squared test and continuous variables by Student's t-test or Mann-Whitney U-test, as appropriate. Multivariate analysis was used to study the independent contribution of polymorphisms with $\mathrm{p}<0.15$ in the univariate analysis. Multiple testing corrections were performed by the permutation test (number of permutations 10000). P values $<0.05$ were considered statistically significant.

\section{Results}

Table 3 shows the genotype distribution of all studied polymorphisms in patients and controls. All polymorphisms included in our study followed the Hardy Weinberg equilibrium in the control group and, except for the ANV5-1C/T polymorphism, when considering all subjects (data not shown).

Prevalence of FVL in the control group was almost thrice than that in patients group $[\mathrm{n}=$ $9(3.1 \%)$ vs. $\mathrm{n}=3(1.1 \%)$, respectively] but this difference was not statistically significant $(\mathrm{p}=0.09)$ (Table 3). However, the 3 patients with FVL allele had 
significantly lower BS median=4, (IQR: 2-4) than the 266 patients without the mutation

BS median=7, (IQR: 5-11, p= 0.013).

None of the other polymorphisms was significantly associated with the BS, both in the whole group of 269 patients and in the cohort of 160 patients with bleeding from unknown cause (data not shown).

Out of the 18 analyzed polymorphisms, three of them (F13 Val34Leu, VKORC1 C1173T and Non-O blood type) were significantly more frequent in the control nonbleeding population than in patients suggesting a bleeding protection. In contrast, carriers of the $\mathrm{T}$ allele of the $F 12-4 \mathrm{C}>\mathrm{T}$ polymorphism were significantly less frequent in controls than in patients, suggesting an associated hemorrhagic risk for this allele (Table 3).

When the analysis was restricted to the 160 patients without a final diagnosis after a complete laboratory work-up, the results were essentially the same, excepting the lack of statistical significance of ABO blood group as compared with the controls (Table 3). Multivariate analysis including polymorphisms with $\mathrm{p}<0.15$ in the univariate analysis revealed that only $F 13$ Val34Leu, VKORC1 C1173T and $\mathrm{ABO}$ polymorphisms maintained their condition of bleeding protection $(\mathrm{OR}=0.66,95 \% \mathrm{CI}: 0.47-0.94$, $\mathrm{p}=0.024 ; \mathrm{OR}=0.59,95 \% \mathrm{CI}: 0.40-0.87, \mathrm{p}=0.009$; and $\mathrm{OR}=0.59,95 \% \mathrm{CI}: 0.41-0.86, \mathrm{p}=$ 0.006, respectively). Identical statistical testing in the patients with unknown diagnosis gave similar results to the univariate analysis.

Multiple testing adjusting by permutation analysis (number of permutations 10,000), did not modify these results (data not shown).

In a framework of a polygenic disease, we evaluated the effect in MCB for the combination of the three polymorphisms that seems to have a role in this disease after the multivariate analysis. The profile with homozygous genotypes of the common allele in the general population for these polymorphisms (F13 Val34Val + VKORC1 C1173C + Blood group $\mathrm{O})$ was taken as the reference category $(\mathrm{OR}=1)$ to calculate the $\mathrm{OR}$ that 
confers all alternative combinations of these three SNPs. As shown in Table 4 the combination of these polymorphisms had an additive protective effect for bleeding risk, which is maximal with the concurrency of the three polymorphisms in the same individual.

\section{Discussion}

The balance between procoagulant and anticoagulant factors is finely tuned to ensure an appropriate, timely and spatially restricted haemostatic response, avoiding its extension beyond the limits of vascular injury and deriving in blood flow obstruction (thrombus formation). In such scenario, it is well known that hypo- or hyperfunction of a singular clotting factor may be causally related to bleeding or thrombosis, respectively. The overwhelming majority of such studies have addressed the risk of thrombosis, but not of bleeding associated with such polymorphisms. The modulating role of common prothrombotic mutations on the bleeding phenotype in severe congenital bleeding disorders $[12,21]$ or in acquired conditions with high bleeding risk or complications $[22,23]$ have been reported. However, such type of studies are lacking in patients with mild bleeding disorders, clinically characterized by MCB.

Although the $\mathrm{ABO}$ system is not an inherent haemostatic polymorphisms, individuals with the O blood group have significantly lower plasma levels of FVIII and VWF than those with non-O blood groups (A, B and $A B)[24,25]$. In our study, we found that $O$ genotype was significantly over-represented in patients as compared with controls. A trend in the same direction was observed in the 160 patients with no etiologic diagnosis. These results support previous ones showing that the $\mathrm{O}$ blood group increases the bleeding risk [26] and protects against both venous [27] and arterial thrombosis [28, 29]. In the same line, our results showed that the non-O blood group exerts a weak protection from bleeding (OR: 0.63 95\% CI: 0.44-0.89). 
We also evaluated the protective role on $\mathrm{MCB}$ of other functional haemostatic polymorphisms with a more controversial pro-thrombotic role. We observed that $F 13$ Leu34 and VKORC1 1173T alleles, whose relationship with thrombosis is still unresolved [30-32] were significantly over-represented in controls than in the whole patient population, as well as in the cohort of patients with unknown diagnosis. Accordingly, these polymorphisms would decrease the hemorrhagic risk. In contrast, the F12 -4T polymorphic allele, also considered a controversial thrombotic risk factor $[33,34]$ was more prevalent in patients than in controls, favoring the bleeding tendency (Table 3).

The multivariate analysis, which incorporated only SNPs with $\mathrm{p}<0.15$ in the univariate analysis, showed that only 3 out of the 18 polymorphisms (F13 Val34Leu, VKORC1 C1173T and ABO blood system) were protective for bleeding.

Currently, our incomplete pathophysiological understanding of bleeding in most patients with skin and mucous hemorrhages precludes the use of specific diagnostic tests and explains why more than $50 \%$ of them end up without a known diagnosis [9]. In this regard, most mild bleeding disorders are likely multi-factorial, with symptoms emerging only after the accretion of less severe hereditary or acquired bleeding risk factors, as demonstrated in venous thrombosis [35]. This notion is founded in several pieces of evidence: A. Combined mild bleeding disorders (i.e., VWD + platelet function defect) are more frequent $(11.5 \%)$ than predicted by chance [10]. B. There is a weak or null correlation of bleeding severity with some laboratory findings, e.g., plasma VWF $[10,11,35]$ or most platelet aggregation defects [10]. C. Acquired conditions (i.e., intake of aspirin) trigger bleeding episodes in up to $44 \%$ of patients with oligosymptomatic hereditary MCB, whereas it seldom induces hemorrhages in healthy subjects. In this regard, the aspirin-induced platelet aggregation and secretion defects in non-bleeder individuals are usually more severe than those of aspirin-free patients diagnosed with platelet secretion disorders [10]. 
This polygenic conception of mild bleeding disorders is supported by the results shown

in Table 4. The reference combination of the 3 polymorphisms identified in the multivariate analysis (F13 Val34Val + VKORC1 C1173C + Blood group O) was present in a patient/control ratio of 1.5 . In contrast, the profile with the combination of our guessed protective alleles (F13 Leu34 + VKORC1 1173T + Blood group Non-O) were found in a patient/control ratio of 0.37 in the whole sample (OR: $0.24 ; 95 \% \mathrm{CI}$ : 0.11-0.52). This protection was slightly increased in bleeders of unknown cause (OR: 0.21; 95\%CI: 0.08-0.52).

The above results strongly support the notion that MCB behaves like a complex disease, similar to our current concept of thrombotic events. Just a minority of the inherited mucocutaneous bleeding disorders have a strong monogenic component (i.e., Glanzmann's thrombasthenia, Bernard-Soulier syndrome) while most of them result from complex combinations of various risk factors whose final effect is tilting the haemostatic balance toward bleeding. Here we showed how different and common functional haemostatic polymorphisms, so far visualized mainly as thrombotic risk factors, may also modulate the bleeding risk. The polygenic conception of MCB is further supported by the additive or synergistic bleeding risks resulting from combinations of polymorphisms in the same patient. Our study does not allow concluding that the studied polymorphisms, even when combined, have enough power to explain per se the bleeding symptoms, but our results do support their modulating role in either preventing or enhancing the bleeding in patients with stronger risk factors, such as low plasma VWF or platelet dysfunctions. In this context, the large clinical heterogeneity of VWD and platelet function diseases may be partially explained by the enhancing or inhibitory role of these polymorphisms.

Our study has some limitations that warrant our attention. First, the choice of SNPs is arbitrary, and other potentially relevant SNPs could be added. We took a hypothesisdriven candidate gene approach rather than a whole genome analysis scan (GWAS) - 
based approach because it was clear that the number of events to be analyzed would be small, and we were intended to identify pertinent functional loci variants with moderate to large functional effect. Future GWAS and sequencing approaches may add relevant variants in other haemostatic elements and unknown pathways that could play a role in MCB. Second, the fact that FXIII and VKORC1 polymorphisms did not follow the HWE in the patient sample questions the suggested protective effect on MCB. Finally, a more stringent multiple testing analysis revealed that only the $\mathrm{ABO}$ blood group maintained its significant effect on MCB. Therefore, further studies with more patients and controls are required to confirm these results.

\section{Funding}

This work was partially supported by 04515/GERM/06 from Fundación Séneca, SAF2006-06212 (MCYT \& FEDER), RETICS (RECAVA) from ISCIII, Programa PCI Iberoamérica A/9351/07 from Ministerio de Asuntos Exteriores y de Cooperación, Spain; and Grant No 1060637 from FONDECYT (Fondo de Desarrollo Científico y Tecnológico), Chile

\section{Acknowledgements}

We are grateful to C. Martínez, J. Rivera, M.L. Lozano and L. Navarro-Núñez for help discussions. 


\section{Referencees}

1. Bertina RM, Koeleman BP, Koster T, Rosendaal FR, Dirven RJ, de Ronde H, et al (1994) Mutation in blood coagulation factor V associated with resistance to activated protein C. Nature 369: 64-67

2. Poort SR, Rosendaal FR, Reitsma PH, Bertina RM (1996) A common genetic variation in the 3'-untranslated region of the prothrombin gene is associated with elevated plasma prothrombin levels and an increase in venous thrombosis. Blood 88: 3698-3703

3. Reitsma PH, Rosendaal FR (2007) Past and future of genetic research in thrombosis. J Thromb Haemos 5: 264-269

4. Ye Z, Liu EH, Higgins JP, Keavney BD, Lowe GD, Collins R, et al (2006) Seven haemostatic gene polymorphisms in coronary disease: meta-analysis of 66,155 cases and 91,307 controls. Lancet 367: 651-658

5. Kyrle PA, Eichinger S (2005) Deep vein thrombosis. Lancet 365: 1163-74

6. Lowe GD (2008) Common risk factors for both arterial and venous thrombosis. Br J Haematol 140: 488-495

7. Nosek-Cenkowska B, Cheang MS, Pizza NJ, Israelí ED, Gerrard JM (1991) Bleeding/bruising symptomatology in children with and without bleeding disorders. Thromb Haemost 65: 237-241

8. Bevan JA, Maloney KW, Hillery CA, Gill, JC, Montgomery RR, Scott JP (2001) Bleeding disorders: A common cause of menorrhagia in adolescents. Journal of Pediatrics 138:856-861

9. Pereira J, Quiroga T, Mezzano D (2008) Laboratory assessment of familial, non-thrombocytopenic mucocutaneous bleeding: a definitive diagnosis is often not possible. Semin Thromb Hemost 34: 654-662

10. Quiroga T, Goycoolea M, Panes O, Aranda E, Martínez C, Belmont S, et al (2007) High prevalence of bleeders of unknown cause among patients with 
inherited mucocutaneous bleeding. A prospective study of 280 patients and 299 controls. Haematologica 92: 357-65

11. Sadler JE (2004) Slippery criteria for von Willebrand disease type 1. J Thromb Haemost 2: 1720-1723

12. van Dijk K, van der Bom JG, Fischer K, Grobbee DE, van den Berg HM (2004) Do prothombotic factors influence clinical phenotype of severe haemophilia? A review of the literature. Thromb Haemost 92:305-310

13. Franchini M, Mannucci PM (2008) Interactions between genotype and phenotype in bleeding and thrombosis. Haematologica 93: 649-652

14. Sramek A, Eikenboom JC, Briet E, Vandenbroucke JP, Rosendaal FR (1995) Usefulness of patient interview in bleeding disorders. Arch Int Med 155: 14091415

15. Freson K, De Vos R, Wittevrongel C, Thys C, Defoor J, Vanhees L, et al (2005) The TUBB1 Q43P functional polymorphism reduces the risk of cardiovascular disease in men by modulating platelet function and structure. Blood 106: 2356-2362

16. Randen I, Sorensen K, Killie M.K, Kjeldsen-Kragh J (2003) Rapid and reliable genotyping of human platelet antigen (HPA)-1, $-2,-3,-4$ and $-5 \mathrm{a} / \mathrm{b}$ and Gov a/b by melting curve analysis. Transfusion $43: 445-450$

17. Shemirani A.H, Muszbek (2004) Rapid detection of the factor XIII Val34Leu $(163 \mathrm{G} \rightarrow \mathrm{T})$ polymorphism by real-time PCR using fluorescence resonance energy transfer detection and melting curve analysis. Clin Chem Lab Med 42: $877-879$

18. Nauck M, Wieland H, März W (1999) Rapid, homogeneous genotyping of the 4G/5G polymorphism in the promoter region of the PAI 1 gene by fluorescence resonance energy transfer and probe melting curves. Clinical Chemistry 45: 
19. Tag CG, Mengsteab S, Weiskirchen R, Kanse SM (2007) Rapid genotyping of the G534E polymorphism (Marburg I) of the gene encoding the factor VIIactivating protease (FSAP) by LightCycler PCR. Clinical Biochemistry 40: 1314

20. Sole X, Guino E, Valls J, Iniesta R, Moreno V (2006) SNPStats: a web tool for the analysis of association studies. Bioinformatics 22:1928-1929

21. Castoldi E, Riemslag JWPG, Pinotti M, Bindini D, Tans G, Berrettini M, et al (2003) Coinheritance of Factor V (FV) Leiden enhances thrombin formation and is associated with a mild bleeding phenotype in patients homozygous for the FVII 9726+5G>A (FVII Lazio) mutation . Blood 102: 4014-4020

22. Lindqvist PG, Dahlbäck B (2008) Carriership of Factor V Leiden and evolutionary selection advantage. Curr Med Chem 15:1541-1544

23. Corral J, Iniesta JA, González-Conejero R, Villalón M, Vicente V (2001) Polymorphisms of clotting factors modify the risk for primary intracranial hemorrhage. Blood 97: 2979-2982

24. O'Donnell J, Laffan MA (2001) The relationship between ABO histo-blood group, factor VIII and von Willebrand factor. Transfusion Medicine 11: 343351

25. Gill C J, Endres-Brooks J, Bauer PJ, Marks WJ, Montgomery RR (1987) The effect of $\mathrm{ABO}$ blood group on the diagnosis of von Willebrand disease. Blood 69: $1691-1695$

26. Ionescu DA, Marcu I, Bicescu E (1976) Cerebral thrombosis, cerebral haemorrhage, and ABO blood-groups. Lancet 1: 278-280

27. Morelli VM, H de Visser MC, Vos HL, Bertina RM, Rosendaal FR (2005) ABO blood group genotypes and the risk of venous thrombosis: effect of factor V Leiden. J Thromb Haemost 3: 183-185 
28. Miñano A, Ordóñez A, España F, González-Porras JR, Lecumberri R, Fontcuberta J, et al (2008) AB0 blood group and risk of venous or arterial thrombosis in carriers of factor V Leiden or prothrombin G20210A polymorphisms. Haematologica 93: 729-734

29. Wiggins KL, Smith NL, Glazer NL, Rosendaal FR, Heckbert SR, Psaty BM, Rice KM, Lumley T (2009) ABO genotype and risk of thrombotic events and hemorrhagic stroke. J Thromb Hemost 7: 263-269

30. Van Hylckama Vlieg A, Komanasin N, Ariëns RA, Poort SR, Grant PJ, Bertina RM, et al (2002) Factor XIII Val34Leu polymorphism, factor XIII antigen levels and activity and the risk of deep venous thrombosis. $\mathrm{Br} \mathrm{J}$ Haematol 119:169-175

31. Gemmati D, Serino ML, Ongaro A, Tognazzo S, Moratelli S, Resca R, et al (2001) A common mutation in the gene for coagulation factor XIII-A (VAL34Leu): a risk factor for primary intracerebral hemorrhage is protective against atherothrombotic diseases. Am J Hematol 67:183-188

32. Smadja DM, Loriot MA, Hindorff LA, Mellottee L, Gaussem P, Emmerich J (2008) No clear link between VKORC1 genetic polymorphism and the risk of venous thrombosis or peripheral arterial disease. Thromb Haemost 99: 970-972

33. Tirado I, Soria JM, Mateo J, Oliver A, Souto JC, Santamaria A, et al (2004) Association after linkage analysis indicates that homozygosity for the $46 \mathrm{C}>\mathrm{T}$ polymorphism in the F12 gene is a genetic risk factor for venous thrombosis. Thromb Haemost 91: 899-904

34. Grünbacher G, Marx-Neuhold E, Pilger E, Köppel H, Renner W (2005) The functional $-4 \mathrm{C}>\mathrm{T}$ polymorphism of the coagulation factor XII gene is not associated with deep venous thrombosis. J Thromb Haemost 3: 2815-2817

35. Rosendaal FR (1999) Venous thrombosis: a multicausal disease. Lancet 353: $1167-1173$ 
TABLE 1. Site, frequency of bleeding and family history in patients with mucocutaneous bleeding and controls.

\begin{tabular}{|c|c|c|c|}
\hline \multirow{3}{*}{ Symptoms } & \multicolumn{3}{|c|}{ Frequency $\%$} \\
\hline & Controls & $\begin{array}{c}\text { All } \\
\text { patient population }\end{array}$ & $\begin{array}{l}\text { Patients with } \\
\text { bleeding of } \\
\text { unknown cause }\end{array}$ \\
\hline & $\mathrm{n}=286$ & $\mathrm{n}=269$ & $\mathrm{n}=160$ \\
\hline Menorrhagia & $1.4(70)^{*}$ & $90.0(90)^{*}$ & $87.8(49)^{*}$ \\
\hline Ecchymoses & 19.6 & 78.8 & 79.4 \\
\hline Epistaxis & 24.1 & 77.3 & 78.1 \\
\hline Cautery & 1.0 & 24.2 & 25.6 \\
\hline Bleeding after dental extractions & $0.0(115)^{*}$ & $66.0(103)^{*}$ & $59.6(57)^{*}$ \\
\hline Gum bleeding & 12.6 & 53.9 & 53.1 \\
\hline Post-partum bleeding & $0.0(8)^{*}$ & $51.7(29) *$ & $64.7(17)^{*}$ \\
\hline Bleeding after minor injuries & 1.4 & 49.4 & 46.9 \\
\hline Surgical bleeding & $0.0(77)^{*}$ & $48.0(102)^{*}$ & $44.6(65)^{*}$ \\
\hline Hematomas (mostly superficial) & 3.1 & 34.2 & 26.9 \\
\hline Bleeding after aspirin intake & $0.0(177)^{*}$ & $31.4(102)^{*}$ & $26.1(69)^{*}$ \\
\hline Bleeding requiring transfusion & 0.0 & 23.4 & 16.9 \\
\hline Hemoptoic sputum & 0.3 & 22.3 & 21.9 \\
\hline Petechiae & 0.7 & 16.0 & 16.3 \\
\hline Occult blood in stools & 1.0 & 14.9 & 15.6 \\
\hline Tongue frenulum bleeding & 0.0 & 9.7 & 9.4 \\
\hline Gastrointestinal bleeding & 0.7 & 7.8 & 6.3 \\
\hline Umbilical bleeding & 0.0 & 7.4 & 9.4 \\
\hline Otorrhagia & 0.0 & 4.5 & 3.1 \\
\hline Hemarthroses & 0.0 & 4.5 & 3.8 \\
\hline Deep hematomas & 0.0 & 0.7 & 0.0 \\
\hline Hematuria & 0.0 & 3.3 & 3.1 \\
\hline Hemoptyses & 0.0 & 0.0 & 0.0 \\
\hline \multicolumn{4}{|l|}{ Family history of bleeding: } \\
\hline -First degree relatives & 23.8 & 28.6 & 33.1 \\
\hline -Second degree relatives & 15.7 & 16.4 & 16.3 \\
\hline -First and second degree relatives & 11.9 & 42.4 & 35.6 \\
\hline Total & 51.4 & 87.4 & 85.0 \\
\hline
\end{tabular}


TABLE 2. Polymorphisms evaluated and method of genotyping.

\begin{tabular}{|c|c|c|c|c|}
\hline Gen symbol & dbSNP & Change & Other name & Genotyping method \\
\hline ITGA2 & rs1126643 & $\mathrm{C} / \mathrm{T}$ (F253) & GPIa C807T & $\begin{array}{l}\text { Taqman SNP Genotyping Assay C__2390370_50 } \\
\text { (Applied Biosystems) }\end{array}$ \\
\hline$A D R A 2 A$ & rs553668 & A/G (3 UTR) & $\begin{array}{c}\text { ADRA2A } \\
\text { G1780A }\end{array}$ & $\begin{array}{l}\text { Taqman SNP Genotyping Assay C__996424_20 } \\
\text { (Applied Biosystems) }\end{array}$ \\
\hline$T U B B 1$ & rs463312 & $\mathrm{A} / \mathrm{C}(\mathrm{Q} 43 \mathrm{P})$ & TUBB Q43P & PCR-ASRA \\
\hline ITGB3 & rs 5918 & T/C (L59P) & GPIIIa HPA-1 & FRET probe \\
\hline$G P I B A$ & rs 6065 & C/T (T161M) & GPIb $\alpha$ HPA-2 & FRET probe \\
\hline$G P I B A$ & VNTR & $23 \mathrm{bp}$ & GPIb $\alpha$ VNTR & $\begin{array}{l}\text { Capillar electrophoresis } \\
\text { Primer F 5'(Hex) CTACTGAACCAACCCCAAGC 3' } \\
\text { Primer R } 5^{\prime} \text { CTTGTGGCAGACACCAGGAT 3' }\end{array}$ \\
\hline$F 2$ & rs1799963 & G/A (3'UTR) & PT G20210A & $\begin{array}{l}\text { Taqman SNP Genotyping Assay C__872602_20 } \\
\text { (Applied Biosystems) }\end{array}$ \\
\hline$F 5$ & rs6025 & G/A (R534Q) & FV Leiden & $\begin{array}{l}\text { Taqman SNP Genotyping Assay C__11975250_10 } \\
\text { (Applied Biosystems) }\end{array}$ \\
\hline$F 7$ & rs36208070 & $10 \mathrm{bp}$ & $\begin{array}{c}F 7-323 \\
\text { ins/del }\end{array}$ & $\begin{array}{l}\text { Capillar electrophoresis } \\
\text { Primer F 5'(Fam) GGTCTGGAGGCTCTCTTCAA3' } \\
\text { Primer R 5`AGAGCGGACGGTTTTGTT3' }\end{array}$ \\
\hline F12 & rs1801020 & C/T (5 UTR) & $F 12-4 \mathrm{C}>\mathrm{T}$ & $\begin{array}{l}\text { Taqman SNP Genotyping Assay C__1989313_20 } \\
\text { (Applied Biosystems) }\end{array}$ \\
\hline F13 & rs5985 & $\mathrm{G} / \mathrm{T}(\mathrm{V} 34 \mathrm{~L})$ & F13 Val34Leu & FRET probe \\
\hline SERPINE1 & rs1799889 & 4G/5G (5UTR) & $P A I-1$ 4G/5G & FRET probe \\
\hline SERPINE10 & rs2232708 & G/A (G271S) & ZPI G250S & \begin{tabular}{|l} 
FRET probe \\
Primer F: 5'CCCATTTGACCCTGTCTTC3' \\
Primer R: 5'CAAAGGTGGAGCCAAACT3' \\
Sensor 5'CACCTGGACAAGTACAAGACCATTAAGGT-Fl 3' \\
Anchor 5'(Red640)CCCATGATGTACAGTGCAGG-P 3'
\end{tabular} \\
\hline ANXA5 & rs11577945 & G/A (5 UTR) & ANV $-1 \mathrm{C} / \mathrm{T}$ & $\begin{array}{l}\text { Taqman SNP Genotyping Assay C__25471553_10 } \\
\text { (Applied Biosystems) }\end{array}$ \\
\hline VKORCI & rs9934438 & $\mathrm{C} / \mathrm{T}$ (intron) & $\begin{array}{l}\text { VKORCl } \\
\text { C1173T }\end{array}$ & $\begin{array}{l}\text { FRET probe } \\
\text { Primer F: 5'GGATAGGGTCAGTGACATGGAAT 3' } \\
\text { Primer R: 5'GCCCGAGAAAGGTGATTT' } \\
\text { Sensor 5'CTAGTCCAAGAGTCGATGATCTCC- Fl 3' } \\
\text { Anchor 5'(Red640)GGCACCGGGCACCTTTGGCC-P 3' }\end{array}$ \\
\hline HAPB2 & rs7080536 & G/A (G534E) & $F S A P$ & FRET probe \\
\hline SELPLG & VNTR & $36 \mathrm{bp}$ & $P S G L-1$ & $\begin{array}{l}\text { Capillar electrophoresis } \\
\text { Primer F 5'(Fam) TCCACGGATTCAGCAGCTAT3' } \\
\text { Primer R 5'GGGAATGCCCTTGTGAGTAA3' }\end{array}$ \\
\hline
\end{tabular}

ITGA2: integrin, alpha 2; GPIa: platelet glycoprotein Ia; $A D R A 2 A$ : adrenergic alpha-2A receptor; TUBB1: tubulin, beta 1; ITGB3: integrin beta 3; GPIIIa: platelet glycoprotein IIIa; HPA-1: human platelet antigen 1; GPIBA: platelet glycoprotein Ib, alpha polypeptide; HPA-2: human platelet antigen 2; F2: coagulation factor II (prothrombin); $F 5$ : coagulation factor V; $F 7$ : coagulation factor VII; F12: coagulation factor XII; F13: coagulation factor XIII; ANXA5: annexin V; PAI-1: plasmin activator inhibitor-1; VKORC1: vitamin K epoxide reductase complex; ZPI: protein Z-related protease inhibitor, HAPB2: hyaluronan binding protein 2; FSAP: factor VII-activating protease; SELPG: selectin P ligand; PSGL-1: P selectin glycoprotein ligand-1. 
TABLE 3. Distribution of genotypes for each polymorphism in patients and controls.

\begin{tabular}{|c|c|c|c|c|c|c|}
\hline & Genotype & $\begin{array}{c}\text { ALL } \\
\text { Patients } \\
\text { n=269 }\end{array}$ & $\begin{array}{c}p \text { value\# } \\
\text { OR }(95 \% \mathrm{CI})\end{array}$ & $\begin{array}{c}\mathrm{UC} * \\
\text { Patients } \\
\text { n=160 }\end{array}$ & $\begin{array}{c}p \text { value\# } \\
\text { OR }(95 \% \mathrm{CI})\end{array}$ & $\begin{array}{l}\text { Controls } \\
\text { n=286 } \\
\end{array}$ \\
\hline \multirow[b]{3}{*}{ GPIa C807T } & $\mathrm{CC}$ & $87(32.3 \%)$ & & $55(34.4 \%)$ & & $94(32.9 \%)$ \\
\hline & $\mathrm{CT}$ & $130(48.3 \%)$ & 0.90 & $77(48.1 \%)$ & 0.75 & $145(50.7 \%)$ \\
\hline & TT & $52(19.3 \%)$ & $1.02(0.72-1.46)$ & $28(17.5 \%)$ & $0.93(0.62-1.41)$ & $47(16.4 \%)$ \\
\hline \multirow{3}{*}{$\begin{array}{l}A D R A 2 A \\
\text { G1780A }\end{array}$} & GG & $113(42.0 \%)$ & & $69(43.1 \%)$ & & $143(50.0 \%)$ \\
\hline & GA & $124(46.1 \%)$ & 0.06 & $67(41.9 \%)$ & 0.16 & $124(43.4 \%)$ \\
\hline & AA & $32(11.9 \%)$ & $1.38(0.99-1.93)$ & $24(15.0 \%)$ & $1.32(0.89-1.95)$ & $19(6.6 \%)$ \\
\hline \multirow{3}{*}{$\begin{array}{l}T U B B 1 \\
\text { Q43P }\end{array}$} & QQ & $221(82.5 \%)$ & & $132(82.5 \%)$ & & $221(78.4 \%)$ \\
\hline & $\mathrm{QP}$ & $45(16.8 \%)$ & 0.19 & $26(16.2 \%)$ & 0.29 & $54(19.1 \%)$ \\
\hline & $\mathrm{PP}$ & $2(0.8 \%)$ & $0.75(0.49-1.15)$ & $2(1.2 \%)$ & $0.77(0.47-1.26)$ & $7(2.5 \%)$ \\
\hline \multirow{3}{*}{$\begin{array}{l}\text { GPIIIa } \\
\text { HPA1 }\end{array}$} & TT & $207(77.0 \%)$ & & $127(79.4 \%)$ & & $234(81.8 \%)$ \\
\hline & $\mathrm{TC}$ & $58(21.6 \%)$ & 0.16 & $31(19.4 \%)$ & 0.53 & $49(17.1 \%)$ \\
\hline & $\mathrm{CC}$ & $4(1.5 \%)$ & $1.35(0.89-2.04)$ & $2(1.2 \%)$ & $1.17(0.72-1.90)$ & $3(1.1 \%)$ \\
\hline \multirow{3}{*}{$\begin{array}{l}\text { GPIba } \\
\text { HPA2 }\end{array}$} & $\mathrm{CC}$ & $203(76.3 \%)$ & & $122(76.7 \%)$ & & $218(76.5 \%)$ \\
\hline & $\mathrm{CT}$ & $62(23.3 \%)$ & 0.96 & $37(23.3 \%)$ & 0.95 & $58(20.4 \%)$ \\
\hline & TT & $1(0.4 \%)$ & $1.01(0.68-1.50)$ & $0(0 \%)$ & $0.99(0.62-1.56)$ & $9(3.2 \%)$ \\
\hline GPIba & $\mathrm{CC}+\mathrm{CD}+\mathrm{DD}$ & $213(79.2 \%)$ & 0.59 & $126(78.25 \%)$ & 0.57 & $226(81.0 \%)$ \\
\hline VNTR & $\mathrm{BB}+\mathrm{BD}+\mathrm{CB}$ & $56(20.8 \%)$ & $1.12(0.74-1.71)$ & $34(21.25 \%)$ & $1.15(0.71-1.86)$ & $53(19.0 \%)$ \\
\hline \multirow[b]{2}{*}{ PT G20210A } & GG & $264(98.1 \%)$ & 0.63 & $158(98.8 \%)$ & 0.37 & $279(97.5 \%)$ \\
\hline & GA & $5(1.9 \%)$ & $0.75(0.24-2.41)$ & $2(1.2 \%)$ & $0.5(0.1-2.46)$ & $7(2.5 \%)$ \\
\hline \multirow{2}{*}{\begin{tabular}{|l|} 
FV \\
Leiden
\end{tabular}} & GG & $266(98.9 \%)$ & 0.09 & $159(99.4 \%)$ & 0.06 & $277(96.8 \%)$ \\
\hline & GA & $3(1.1 \%)$ & $0.35(0.09-1.30)$ & $1(0.6 \%)$ & $0.19(0.02-1.54)$ & $9(3.1 \%)$ \\
\hline \multirow{3}{*}{$\begin{array}{l}F 7 \\
-323 i n s / d e l \\
\end{array}$} & AA & $198(73.6 \%)$ & & $118(73.8 \%)$ & & $191(66.8 \%)$ \\
\hline & $\mathrm{AB}$ & $66(24.5 \%)$ & 0.08 & $40(25.0 \%)$ & 0.12 & $87(30.4 \%)$ \\
\hline & $\mathrm{BB}$ & $5(1.9 \%)$ & $0.72(0.50-1.04)$ & $2(1.2 \%)$ & $0.72(0.47-1.1)$ & $8(2.8 \%)$ \\
\hline \multirow{3}{*}{$\begin{array}{l}F 12 \\
-4 \mathrm{C}>\mathrm{T} \\
\end{array}$} & $\mathrm{CC}$ & $103(38.3 \%)$ & & $58(36.2 \%)$ & & $136(47.5 \%)$ \\
\hline & CT & $133(49.4 \%)$ & 0.03 & $79(49.4 \%)$ & 0.02 & $123(43.0 \%)$ \\
\hline & TT & $33(12.3 \%)$ & $1.46(1.04-2.05)$ & $23(14.4 \%)$ & $1.59(1.07-2.37)$ & $27(9.4 \%)$ \\
\hline \multirow{3}{*}{$\begin{array}{l}F 13 \\
\text { Val34Leu }\end{array}$} & GG & $147(54.9 \%)$ & & $90(56.6 \%)$ & & $123(43.0 \%)$ \\
\hline & GT & $93(34.7 \%)$ & 0.005 & $51(32.1 \%)$ & 0.005 & $137(47.9 \%)$ \\
\hline & TT & $28(10.4 \%)$ & $0.62(0.44-0.87)$ & $18(11.3 \%)$ & $0.58(0.39-0.86)$ & $26(9.1 \%)$ \\
\hline \multirow{3}{*}{$\begin{array}{l}\text { PAI-1 } \\
\text { 4G/5G }\end{array}$} & $5 \mathrm{G} 5 \mathrm{G}$ & $95(35.3 \%)$ & & $57(35.6 \%)$ & & $98(34.3 \%)$ \\
\hline & $4 \mathrm{G} 5 \mathrm{G}$ & $126(46.8 \%)$ & 0.80 & $75(46.9 \%)$ & 0.7 & $132(46.1 \%)$ \\
\hline & $4 \mathrm{G} 4 \mathrm{G}$ & $48(17.8 \%)$ & $0.95(0.67-1.35)$ & $28(17.5 \%)$ & $0.94(0.63-1.41)$ & $56(19.6 \%)$ \\
\hline \multirow[b]{2}{*}{ ZPI G250S } & GG & $264(98.1 \%)$ & 0.84 & $157(98.1 \%)$ & 0.87 & $279(97.9 \%)$ \\
\hline & GA & $5(1.9 \%)$ & $0.88(0.27-2.92)$ & $3(1.9 \%)$ & $0.89(0.22-3.60)$ & $6(2.1 \%)$ \\
\hline \multirow{3}{*}{$\begin{array}{l}A N X 5 \\
-1 \mathrm{C} / \mathrm{T} \\
\end{array}$} & $\mathrm{CC}$ & $222(82.5 \%)$ & & $128(80.0 \%)$ & & $226(79.0 \%)$ \\
\hline & CT & $47(17.5 \%)$ & 0.29 & $32(20.0 \%)$ & 0.81 & $59(20.6 \%)$ \\
\hline & TT & $0(0 \%)$ & $0.80(0.52-1.22)$ & $0(0 \%)$ & $0.94(0.58-1.52)$ & $1(0.4 \%)$ \\
\hline \multirow{3}{*}{$\begin{array}{l}\text { VKORC1 } \\
\text { C1173T }\end{array}$} & $\mathrm{CC}$ & $93(34.7 \%)$ & & $60(37.7 \%)$ & & $71(25.0 \%)$ \\
\hline & $\mathrm{CT}$ & $113(42.2 \%)$ & 0.013 & $66(41.5 \%)$ & 0.005 & $144(50.7 \%)$ \\
\hline & TT & $62(23.1 \%)$ & $0.63(0.43-0.91)$ & $33(20.8 \%)$ & $0.55(0.36-0.84)$ & $69(24.3 \%)$ \\
\hline \multirow{2}{*}{$\begin{array}{l}\text { FSAP } \\
\text { G534E }\end{array}$} & GG & $264(98.1 \%)$ & 0.82 & $155(96.9)$ & 0.52 & $276(97.9 \%)$ \\
\hline & GA & $5(1.9 \%)$ & $0.87(0.26-2.89)$ & $5(3.1 \%)$ & $1.48(0.45-4.94)$ & $6(2.1 \%)$ \\
\hline \multirow{2}{*}{$\begin{array}{l}\text { PSGL1 } \\
\text { VNTR }\end{array}$} & AA & $195(72.5 \%)$ & 0.84 & $108(67.5 \%)$ & 0.19 & $211(73.8 \%)$ \\
\hline & $\mathrm{AB}+\mathrm{AC}+\mathrm{BB}$ & $72(27.5 \%)$ & $1.04(0.71-1.52)$ & $51(32.5 \%)$ & $1.32(0.86-2.03)$ & $75(26.2 \%)$ \\
\hline \multirow[b]{2}{*}{$A B O$} & $\mathrm{O}$ & $184(68.4 \%)$ & 0.009 & $106(66.2 \%)$ & 0.074 & $165(57.7 \%)$ \\
\hline & No-O & $85(31.6 \%)$ & $0.63(0.44-0.89)$ & $54(33.8 \%)$ & $0.69(0.46-1.04)$ & $121(42.3 \%)$ \\
\hline
\end{tabular}

* UC: Unknown Cause.

\# OR were calculated taking as reference category the most frequent homozygous genotypes of each polymorphism in the general population or combination of genotypes for the GPIb $\alpha$ VNTR. 
TABLE 4. Additive effect of combination of polymorphisms on the risk of developing MCB.

\begin{tabular}{|c|c|c|c|c|c|}
\hline Polymorphisms combinations ${ }^{\#}$ & $\begin{array}{c}\text { All } \\
\text { Patients } \\
\text { n=269 }\end{array}$ & $\begin{array}{c}p \text { value } \\
\text { OR }(95 \% \text { CI })\end{array}$ & $\begin{array}{c}\mathrm{UC} * \\
\text { Patients } \\
\text { n=160 }\end{array}$ & $\begin{array}{c}p \text { value } \\
\text { OR }(95 \% \text { CI })\end{array}$ & $\begin{array}{c}\text { Controls } \\
\text { n=286 } \\
\end{array}$ \\
\hline F13 Val34Val \& VKORC1 C1173C \& O ABO & 33 & $\begin{array}{c}\text { Reference } \\
1\end{array}$ & 22 & $\begin{array}{c}\text { Reference } \\
1\end{array}$ & 22 \\
\hline F13 Leu34 \& VKORC1 1173T & 82 & $\begin{array}{c}0.002 \\
0.44(0.24-0.81)\end{array}$ & 43 & $\begin{array}{c}0.001 \\
0.34(0.17-0.69)\end{array}$ & 123 \\
\hline F13 Leu34 \& no-O ABO & 37 & $\begin{array}{c}0.004 \\
0.36(0.18-0.72) \\
\end{array}$ & 24 & $\begin{array}{c}0.034 \\
0.35(0.1-0.76) \\
\end{array}$ & 67 \\
\hline VKORCl $1173 \mathrm{~T} \&$ no-O ABO & 46 & $\begin{array}{c}<0.001 \\
0.32(0.17-0.62) \\
\end{array}$ & 29 & $\begin{array}{c}0.001 \\
0.30(0.14-0.63) \\
\end{array}$ & 94 \\
\hline F13 Leu34 \& VKORC1 $1173 \mathrm{~T} \&$ no-O ABO & 19 & $\begin{array}{c}<0.001 \\
0.24(0.11-0.52)\end{array}$ & 11 & $\begin{array}{c}0.001 \\
0.21(0.08-0.52) \\
\end{array}$ & 51 \\
\hline
\end{tabular}

* UC: Unknown Cause.

\#F13 Leu34 includes F13 Val34Leu and F13 Leu34Leu genotypes.

VKORC1 1173T includes VKORC1 C1173T and VKORC1 T1173T genotypes. 


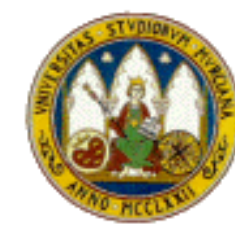

UNIVERSIDAD

DE MURCIA

DEPARTAMENTO DE

MEDICINA INTERNA

Facultad de Medicina

Murcia, $10^{\text {th }}$ May 2010,

Dear Dr. Ganser,

Thank you for considering our manuscript "Mucocutaneous bleeding disorders: role on development and severity of bleeding of 18 common hemostatic polymorphisms", by

A.I. Antón et al., potentially publishable in Annals of Hematology.

We feel really grateful to all the reviewers and have tried to answer all their questions and meet all their demands. Accordingly, we would like you to re-consider this revised version of the manuscript for publication in Annals of Hematology.

The point-by-point explanation of changes made to the original manuscript ensue within what the next following pages.

We hope that all comments and corrections satisfy the reviewers criticisms and that now our manuscript be accepted for publication in this journal..

We look forwards to hearing from you soon.

Yours sincerely,

Prof. V Vicente. 


\section{$\underline{\text { Reviewer 1: }}$}

In their study entitled "Mucocutaneous bleeding disorders: role on development and severity of bleeding of 18 common haemostatic polymorphisms." Antón et al analyzed arbitrarily selected known polymorphisms in genes of procoagulatory and anticoagulatory proteins for an association with mucocutaneous bleeding. They tested 269 patients and 286 controls in a case control study design. The authors identified three components (non-O blood group, F13 Leu34 and VKORC1 1173T) to protect from mucocutaneous bleeding in a statistically significant fashion.

The study is interesting, and the conclusion that mild bleeding disorders are not caused by genetic defects in one gene but are polygenic and multifactorial similar to thrombotic disorders, is plausible. However, besides the arbitrary selection of the 18 SNPs the study has several major limitations that have to be addressed:

Only 160 patients had unexplained bleeding disorders, in 109 patients platelet defects, vWD or coagulation factor deficiencies were identified. Thus, the number of patients with unexplained bleeds was small and the study has to be considered a hypothesis finding study. The authors have to make this very clear (eg. in the title).

We acknowledge the appropriate comments from reviewer 1 . We agree that this study is an hypothesis finding study and the title was modified accordingly. Moreover, we have moderated our conclusions both in the Abstract and Discussion sections.

Additionally, we have explained the selection of the studied polymorphisms in the introduction section. These 18 polymorphisms have a relevant effect on different hemostatic proteins, as they affect the levels, function or aminoacid sequence, and all have been evaluated in different hemostatic diseases, mainly thrombotic disorders. Certainly, other polymorphisms of the haemostatic system could follow this criteria, but 
with more controversial effects, low prevalence or less number of studies supporting their functional role in thrombosis.

The authors have to test the distribution of their genotypes for Hardy Weinberg equilibrium. Clearly, in the patient population the FXIII polymorphism significantly deviates from the Hardy Weinberg distribution $(\mathrm{p}=0.0149)$. Possibly, technical problems or a selection bias is responsible for this deviation. Undoubtedly, data that deviate from Hardy Weinberg cannot be used for statistical calculations! The distribution for VKORC1 is also borderline in the patients!

We acknowledge and understand the reviewer's concerns about deviations of the Hardy Weinberg equilibrium (HWE) in our study. Potential technical problem of genotyping were discarded by consistent results between genotyping and sequencing analysis performed in random samples for all polymorphisms. There are several explanations why the observed genotype frequencies may deviate significantly from those expected by HW law and why genotypes have different likehoods of being included, even when determination of genotype was methodologically correct. One or more of the assumptions of the model might be incorrect, non-random mating (inbreeding or an allele effect on the mating) or gene flow may have occurred, or selection operated (Sham P. Statistics in human genetics. New York, NY: Oxford University Press, 1998). There could also be an error at sampling: the studied population is not well defined or the sample size may be too small. If the genotype distribution in the control population misses the HWE, the results should be treated cautiously because the observed genotype distribution does not represent the genotype distribution in healthy (non-diseased) people and, therefore, conclusions cannot be drawn for the significance of the 
investigated polymorphism. All polymorphisms included in our study followed the HWE in the control group and, except for the ANV5 -1C/T, when considering all subjects (Table A). This statement has been included in the revised manuscript (line 19, page 6). However, relationship between genotype and disease might occur if the genotype distribution in the investigated (diseased) population does not fulfill the HWE law while the healthy reference population does it (Lee WC. Searching for diseasesusceptibility loci by testing for Hardy-Weinberg disequilibrium in gene bank of affected individuals. American Journal of Epidemiology; 2003 (5):397-400). Nevertheless, we agree with reviewer 1 that deviation of $F 13$ and VKORC1 polymorphisms of patient population from the HWE questions the role of these two polymorphisms in MCB. This limitation has also been included in the revised manuscript (line 5, page 11). 
Table A. Exact test for Hardy Weinberg equilibrium for all studied polymorphisms

\begin{tabular}{|lc|c|c|}
\hline \multicolumn{2}{|c|}{ Patients } & Controls & All subjects \\
\hline $\begin{array}{l}\text { GPIa } \\
\text { C807T }\end{array}$ & 0.8 & 0.54 & 0.79 \\
\hline $\begin{array}{l}\text { ADRA2A } \\
\text { G1780A }\end{array}$ & 0.89 & 0.31 & 0.43 \\
\hline $\begin{array}{l}\text { TUBB1 } \\
\text { Q43P }\end{array}$ & 1 & 0.15 & 0.26 \\
\hline $\begin{array}{l}\text { GPIII } \\
\text { HPA1 }\end{array}$ & 1 & 0.73 & 0.83 \\
\hline $\begin{array}{l}\text { GPIba } \\
\text { HPA2 }\end{array}$ & 0.14 & 0.066 & 0.7 \\
\hline $\begin{array}{l}\text { GPIba } \\
\text { VNTR }\end{array}$ & $*$ & $*$ & $*$ \\
\hline $\begin{array}{l}\text { PT } \\
\text { G20210A }\end{array}$ & 1 & 1 & 1 \\
\hline $\begin{array}{l}\text { FV } \\
\text { Leiden }\end{array}$ & 1 & 1 & 1 \\
\hline $\begin{array}{l}\text { F7 } \\
\text {-323ins/del }\end{array}$ & 1 & 0.69 & 0.75 \\
\hline $\begin{array}{l}\text { F12 } \\
\text {-4C }>\text { T }\end{array}$ & 0.36 & 1 & 0.51 \\
\hline $\begin{array}{l}\text { F13 } \\
\text { Val34Leu }\end{array}$ & 0.032 & 0.18 & 0.62 \\
\hline $\begin{array}{l}\text { PAI-1 } \\
\text { 4G/5G }\end{array}$ & 0.61 & 0.34 & 0.3 \\
\hline $\begin{array}{l}\text { ZPI } \\
\text { G250S }\end{array}$ & 1 & 1 & 1 \\
\hline $\begin{array}{l}\text { ANX 5 } \\
\text {-1C/T }\end{array}$ & 0.24 & 0.22 & 0.048 \\
\hline $\begin{array}{l}\text { VKORC1 } \\
\text { C1173T }\end{array}$ & 0.019 & 0.91 & 0.12 \\
\hline $\begin{array}{l}\text { FSAP } \\
\text { G534E }\end{array}$ & 1 & 1 & 1 \\
\hline $\begin{array}{l}\text { PSGL1 } \\
\text { VNTR }\end{array}$ & $*$ & $*$ & $*$ \\
\hline ABO & $*$ & $*$ & $*$ \\
\hline HWE & & & \\
\hline
\end{tabular}

* HWE not determined for multiallelic polymorphisms.

The performance of functional assays e.g. for FXIII, FVIII or FXII would be highly valuable to proof that carriers of the SNPs or non-O blood group had indeed lower or higher coagulation factor levels, respectively.

The functional effect of FXIII, FVIII or FXII polymorphisms have been deeply investigated and evidenced elsewhere, also by our group. Moreover, in this study, we 
have also demonstrated the effect of $F 12-4 \mathrm{C}>\mathrm{T}$ polymorphism and $\mathrm{O}$ blood group on plasma levels of hemostatic factors. As shown in Table B, carriers of F12 -4T allele had significantly lower levels of FXII in plasma than carriers of the C allele. Similarly, O blood group carriers had lower levels of FVIII and VWF than carriers of no-O blood type. Unfortunately, we have no data for FXIIIc levels or activity, but others studies have demonstrated the functional effect of the F13 V34L polymorphism (Ariëns RA, Philippou H, Nagaswami C, Weisel JW, Lane DA, Grant PJ. The factor XIII V34L polymorphism accelerates thrombin activation of factor XIII influencing the stabilization of the fibrin clot (Blood. 2000 Aug 1;96(3):988-95).

TABLE B. Functional effect of F12 and ABO polymorphisms on FXII, FVIII and VWF levels in plasma. Values represented the $\%$ of the value observed in a pool of 100 healthy blood donors.

\begin{tabular}{|l|l|l|l|}
\hline F12 -4 C>T & N & FXII & \\
\hline CC & 238 & $109.34 \pm 20.72$ & \\
\hline CT & 256 & $90.72 \pm 20.74$ & \\
\hline TT & 60 & $60.57 \pm 16.24$ & \\
\hline ABO blood type & N & FVIII $<0.0001$ & \\
\hline O Group & 349 & $78.77 \pm 26.10$ & VWF \\
\hline Non-O Group & 206 & $94.37 \pm 29.22$ & $101.48 \pm 39.94$ \\
& & $\mathrm{p}<0.0001$ & $\mathrm{p}<0.0001$ \\
\hline
\end{tabular}


The authors should discuss why they believe that VKORC1 $1173 \mathrm{~T}$ confers a protection from bleeding.

It has been widely reported that the VKORC1 haplotypes regulate the transcription rate of VKORC1. Thus, VKORC1 polymorphisms influence the anticoagulant therapy and the risk of bleeding associated with this treatment. The $\mathrm{C} 1173 \mathrm{~T}$ variant is in high linkage disequilibrium with $-1639 \mathrm{G}>\mathrm{A}$ polymorphisms $\left(\mathrm{r}^{2}=0.946\right)$, and both have been considered as good markers of interindividual variability in VKORC1 activity (Wang D et al., Regulatory polymorphisms in vitamin K epoxide reductase complex subunit 1 (VKORC1) affects gene expression and warfarin dose requirements. Blood 2008; 112:1013). Carriers of $1173 \mathrm{~T}$ or $-1639 \mathrm{~A}$ alleles have a lower mRNA VKORC1 and hence, they need a lower coumarin dose for anticoagulation treatment. The potential role of this polymorphism on the haemostatic system without oral anticoagulation has been investigated without clear consensus. The available data about VKORC1 genotype and risk/protection from thrombosis or bleeding are nowadays conflictive. Thus, a lower risk of VKORC1 genotype on large-artery atherosclerotic stroke have been recently described (Shyu HY et al. Genotype polymorphisms of GGCX, NQO1, and VKORC1 genes associated with risk susceptibility in patients with large-artery atherosclerotic stroke. Clin Chim Acta, 2010; 411:840) whereas others authors fail to find such association in other thrombotic pathologies (Arnold ML et al. Single nucleotide polymorphisms in the VKORC1 gene and the risk of stroke in the Southern German population. Throm Haemost 2008, 100:614; Lemmens, J et al. Lack of association between variants in the VKORC1 gene and cerebrovascular or coronary heart disease (Thromb Haemost 2008; 6:2220; Smadja DM et al.). No clear link between $\mathrm{VKORC1}$ genetic polymorphism and the risk of venous thrombosis or 
peripheral arterial disease. Thromb Haemost 2008; 99:970; Lacut K et al. Vitamin K epoxide reductase genetic polymorphism is associated with venous thromboembolism: results from the EDITH Study. J Thromb Haemost 2007; 5:2020).

In this framework, we considered of interest to evaluate the role of VKORC1 genotype on bleeding risk. Certainly, our findings suggesting that VKORC1 $1173 \mathrm{~T}$ confers a mild protection from bleeding lack a pathophysiological explanation and require further confirmation.

No correction for multiple testing was performed, the authors have to explain why they did not do that and thus cannot exclude statistical associations due to chance.

We appreciate the comment from reviewer 1. Multiple testing corrections adjust pvalues derived from multiple statistical test to correct for occurrence of false positives. This correction is required for massive microarray data analysis, meta-analysis or genome wide association studies, where thousands of genes or SNPs are analyzed simultaneously in different conditions. Our study included only 18 polymorphisms, however, we agree with reviewer 1 than correction for multiple testing would be desirable. Therefore, we performed this analysis by the permutation test (number of permutations: 10,000, $\mathrm{p}<0.05$ ). As indicated in the revised manuscript (line 9, page 7), all polymorphisms maintained the statistical significance. P-values corrected according to permutation test (PT) are shown in table C. 
Table C. Crude and multiple testing adjustment by permutation test (with 10000 permutations) for differences in polymorphisms between patients and controls.

\begin{tabular}{lll} 
& Crude $p$-value & Adjusted p-value $(P T)$ \\
\hline F12 $-4 \mathrm{C}>\mathrm{T}$ & 0.030 & 0.024 \\
F13 Val34Leu & 0.005 & 0.004 \\
VKORC1 C1173T & 0.013 & 0.023 \\
ABO & 0.009 & 0.008
\end{tabular}

However, we admit that more stringent multiple testing analysis (Bonferroni or Benjamini and Hochberg adjustments) reveals that only the ABO blood group maintained its significant effect on MCB. This limitation has also been described in the revised manuscript (line 7 , page 11). 


\section{Reviewer 2:}

Reviewer \#2: Please add a more detailed description of the employed criteria and the whole process of selection of the tested SNPs.

We tested these 18 polymorphisms because they have a relevant functional effect on the affected protein and all have been evaluated in different hemostatic diseases, mainly thrombotic disorders. Certainly, other polymorphisms of the haemostatic system could follow this criteria, but with more controversial effects, low prevalence or less number of studies supporting their functional or pro-thrombotic effect. This is specifically indicated in line 11, page 4 of the revised manuscript. Moreover, not-directed analysis could also have been performed, but due to economical cost, size and heterogeneity of the case-control study, this approach was discarded.

Were other haemostasis associated SNPs genotyped in the present sample, but not included in this publication?

We have recently published a manuscript evaluating the effect on the platelet function of 6 polymorphisms affecting platelet proteins in the same patient and control populations (Martínez C, Antón AI, Corral J, Quiroga T, Panes O, Lozano ML, González-Conejero R, Teruel R, Navarro-Núñez L, Pereira J, Mezzano D, Vicente V, Rivera J. Genotype-phenotype relationship for six common polymorphisms in genes affecting platelet function from 286 healthy subjects and 160 patients with mucocutaneous bleeding of unknown cause. Br J Haematol. 2009 Jun; 146(1):95-103), but no additional polymorphisms were evaluated in this case-control study. 
How do you explain the lack of association of the clinical severity of

bleeding (measured as the bleeding score) with the load of alleles

determined to be risk-factors for MCB?

This is an interesting question. The explanation may be similar to that described for thrombosis. The polymorphism may increase the risk to develop an event but it is not necessarily related to the severity of the event. Only FV Leiden, which is in our opinion the strongest polymorphism on the hemostatic system may have both functions, e.g. protection against mucocutaneous bleeding (the low prevalence of this polymorphism did not allow to get statistical significance in our study) and reduction in the severity of the bleeding.

Discussion on FV leiden is a bit too detailed, considering the low case number, and the not statistical significant results.

We agree with reviewer 2. This is new evidence supporting the differential effect of FV Leiden in thrombosis and hemorrhage, but certainly our results were not statistically significant due to the low case number. Accordingly and following the suggestion of reviewer 1 , we deleted this discussion.

Page 6 line 45: Table 3 does not give the bleeding score

We apologize for the mistake, which has been corrected in the revised manuscript. 